\title{
Monitoring urban development for environmental sustainability in Portugal
}

\author{
T. Fidelis \\ Department of Environment and Planning, University of Aveiro, Portugal
}

\begin{abstract}
The monitoring of urban development has a special role to play in the search for environmental sustainability at the local level. It may enable the assessment of policies and planning strategies as well as the improvement of accountability and effectiveness in urban governance. When urban planning has to articulate sustainability objectives, both internally, within urban areas, and externally, when there are nearby natural areas, monitoring may reveal itself to be of increased relevance. This paper critically analyses local plan evaluation in Portugal in the light of the current theoretical debate on monitoring urban development control. A focus is given to the role and requisites of such evaluation, as well as the prediction of likely challenges during its implementation in the Portuguese context. The case study is centred on the urban master plan and associated implementation reports of the Municipality of Aveiro, close to a littoral wetland area, which constitute, so far, unique examples of a local planning monitoring process in Portugal.

Keywords: monitoring, urban development control, environmental conservation.
\end{abstract}

\section{Introduction}

Promoting and publicising urban monitoring has a special role to play in the search for environmental sustainability at the local level. It may enable the assessment of urban planning and development control, and, consequently, the improvement of accountability and effectiveness of urban planning and governance Voogd [1]. While there are no conclusive arguments as regards the specific relationship between urban features such as size, density or configuration of new urban developments on the one hand, and the related best options for urban sustainability on the other, periodic monitoring is required. 
When urban governance and planning strategies have to articulate various sustainability objectives, both internally, within urban areas, as well as externally, when there are nearby classified natural areas, monitoring may reveal itself to be of increased relevance. Urban areas are known to have significant intrusive effects on their surroundings. The environmental impacts and costs of urbanization have been widely characterized by the scientific community [2]. These include the fragmentation and destruction of habitats and loss of agricultural land, as well as air pollution, mainly caused by vehicles; water pollution, associated with parking lots and roads which accumulate oil and become sources of non-point pollution; and the discharge of polluted runoff water into streams and lakes. When cities are located in the vicinity of environmentally sensitive areas, development control must integrate a spatial approach in articulating urban growth with environmental protection. Chapter 15 of Agenda 21 [3], related to the conservation of biodiversity, refers the need to "promote environmentally sound and sustainable development in areas adjacent to protected areas with a view to furthering protection of these areas". Monitoring and assessment of urban development patterns may contribute to this objective. Chapter 7 of Agenda 21, related to human settlements, also refers the importance of "collection, analysis and dissemination of urban data, including environmental impact analysis, at the local level". The purpose of this paper is to summarise the current theoretical debate on the contribution of monitoring urban development to the protection of natural and environmental values and also to critically analyse a case study about plan evaluation in the Portuguese context.

\section{Urban environmental sustainability and planning monitoring}

A sustainable system can be defined as a system that does not destroy the preconditions of its own existence. By definition, a city, as such, cannot be sustained unless all of its (relevant) components are sustainable. In addition, and because, the sustainability of a system is dependent on an external system, it cannot be evaluated without also examining the external system [4]. In the theoretical debate, the notion of "strong sustainability" has been developed [5] and it requires the identification and implementation of models for urban sustainability. In addition, it requires that special attention be paid to those essential ecological assets which are deemed to constitute critical natural capital [6]. Nearby natural areas and their associated biodiversity are integral parts of this capital and have key importance for sustainability. Among other goals underlying the promotion of sustainable cities is the minimisation of the consumption of space and natural resources EEA [7]. Cities located in the vicinity of natural areas should carefully manage consumption of soil and the convergence of urban sprawl towards the limits of the natural areas. Comprehensive and systematic monitoring schemes may contribute to such a task. 
Within the context of ecosystem protection and urban development control, planning monitoring should be designed to determine whether development actions are articulated with the objectives of ecosystem sustainability. Urban development monitoring schemes have been widely proposed EEA [8] but for small local authorities these often require excessively high investment in terms of human and technical resources. Although there are a number of examples of case studies and regulations for urban planning monitoring, wide and systematic use is still infrequent. Urban growth management policies and instruments, especially those aiming at protecting open and natural spaces, are at the centre of the issue of sustainable development and are in strong need of empirical evaluations [2].

Monitoring means watching and checking something over a period of time in order to see how it develops, so that any necessary changes can be made. Evaluation is the process of converting monitoring data into information and then into knowledge. It is a value-added process which is designed to produce better decision-making. The promotion of a valuable monitoring process, seen as an adaptive management process [9], depends upon a strong conceptual framework which enables the structuring and organization of ideas that underlie the development and interpretation of monitoring. Hoering \& Seasons [10] point out several key issues in monitoring: (i) clear definition of objectives, to be used as references against which evolution is assessed; (ii) use of suitable data, evaluation methodologies and appropriate spatial and temporal scales; (iii) institutionalization of monitoring, assuring that it becomes mandatory and is undertaken systematically; and (iv) public recognition of the importance of monitoring. On the one hand, the public needs to understand the importance of monitoring in determining how the planning activity actually impacts common environmental assets. On the other hand, the public needs to understand that management decisions and planning policy may be improved by the outcome of monitoring and evaluation efforts.

As obstacles to effective monitoring Hoering \& Seasons [10] mentions the unwillingness of local managers to risk, admit or report failure and the differing interpretations of monitoring and conflicting perspectives on what action to take. A local planning monitoring exercise must be understood as an institutional learning process whereby, and in spite of the risks of data manipulation, the organization strongly benefits when evaluation reports are prepared by internal teams [11].

In an environmentally sensitive location and in the absence of formal and comprehensive strategic environmental assessment processes, as in the case study presented later in this paper, monitoring of urban planning and decisionmaking processes acquires an increased level of relevance.

\section{Legal framework for urban planning assessment in the Portuguese context}

The principal features of the current legal framework for urban planning are established by the Framework Law on Territorial and Urban Planning (Law 
$48 / 98$ of 11/08) and related regulations. The main objective of this law is to define and integrate actions which will promote economically, socially and culturally integrated and sustainable development of the country, its various regions and urban centres. It also establishes the structure and hierarchy of planning instruments and their specific functions. This law introduced an innovative view of the planning process by establishing the need to promote evaluation of planning policies and decisions. Additional Decrees have since then been enacted in order to specify the implementation of many of the principles enshrined in the previous law, namely, the articulation between the national, regional and local levels of planning, the broad guidelines for land-use, and the process of plan elaboration, approval and evaluation.

According to current regulations, the national planning authority, the regional development coordination commissions and the municipalities are responsible for preparing a report on the evaluation of plans every two years. Such an evaluation process is to be supported by the establishment of a planning observatory and a national data base. The regulations also establish that evaluation reports may propose changes to plans or plan making procedures. Among the plans to be assessed are the local master plans which establish the main zoning system for a municipality as well as the broad basis for the control of urban development. The responsibility for drawing up such plans lies with the municipality, although they also have to be approved by central government. Although prepared under previous regulations, the existing Local Master Plans were adopted during the nineties. The accumulated documented experience since that time, has enabled a critical review of the planning process in Portugal and brings to the fore the need for plan evaluation [12]. One major criticism focuses on the lack of success in integrating environmental issues [13]. In fact, it is frequently stated that land-use planning has not only been unable to prevent environmental problems but that is has, itself, contributed to several new ones. These include the urbanization of flood plains and other environmentally sensitive zones as well as the licensing of high urban densities in the surrounding areas. Environmental problems related to land-use planning constitute an emerging concern in Portuguese society and largely account for the importance attributed to planning by both the Constitution and an important set of laws. The evaluation process is a fundamental key-step in the promotion of quality and efficacy of planning. A critical analysis of both positive and erroneous decisions taken during land-use planning may enable the correction of negative effects, and provide best practice guidelines.

Although the main objectives of plan evaluation have been defined in legal documents, no methodologies or procedures have been established for undertaking it. So far, and despite what was foreseen, the national data base and planning observatory have not been implemented. Some scattered examples of tentative plan evaluation may exist. However, comprehensive plan evaluation, as established by the new legislation, is yet to be put into practice in Portugal. The case study of the Aveiro Master Plan, presented in the next section, can be considered an exception. It includes some embryonic features of a plan evaluation process and may help identify relevant insights. 


\section{Master plan assessment reports in Aveiro, Portugal}

\subsection{Brief view over development planning in Aveiro}

The Municipality of Aveiro, Figure 1 is located $250 \mathrm{~km}$ north of Lisbon, and $60 \mathrm{~km}$ south of Porto. The municipality has about 70000 inhabitants, and it is inserted in a dynamic and fast-growing industrial region. The history of the growth of Aveiro is linked to the impact the lagoon called "Ria de Aveiro", a relevant estuarine area along the Portuguese coast covering over 11,000 hectares. "Ria de Aveiro" is one of the most important wetland areas in the northern part of Portugal. It includes a Nature Reserve and a large area integrated in 'Natura 2000'. The wetland area is suffering from serious development pressures from the agricultural, industrial, tourism and urban sectors. Its integration in a complex, institutional jurisdictional structure, involving 10 municipalities and several regional and central government departments have hindered the definition and adoption of adequate integrated planning and management strategies for the "Ria de Aveiro", clarifying the role of each municipality regarding the protection of the sensitive wetland area from the negative environmental impacts of development pressures.

From the 1940s to the present day, various stages in the urban development planning for the city have occurred. These include the preparation of a set of various plans like the Physical Land Use Plan by Moreira da Silva in the 1950s, the City Master Plan by Auzelle in the 1960s, the General Urbanization Master Plan by Macroplan in the 1980s, or the Municipal Master Plan by Sá in the 1990s. The influence of this succession of plans on the development patterns and land-use decision-making of the city, however, was ever hardly assessed.

The 1995 Aveiro Master Plan is the main planning instrument the municipality has had for development control. It is a blue-print plan and was the first to cover the whole municipality. In spite its extensive analysis of the local situation, its conformity with central requirements and its response to some local expectations, it gave rise to a number of criticisms during public discussion and the final approval process. Some of these criticisms related to the low workability of the plan, its insufficient linkages to other existing plans and its inadequacy in terms of some local features. These criticisms led the Local Parliament to require the Local Council to prepare annual reports evaluating the implementation of the master plan. Such reports should include a map with all permitting processes, related urban typologies and a critical review of the suitability of all the measures and decision-making concomitant to the plan (Aveiro Master Plan Regulations, Resolution of the Council of Ministers, $165 / 95$, of $11 / 12$, art. $^{\circ} 49^{\circ}, 2$ ). The objectives underlying these reports constitute, so far, a unique example of a local planning assessment process in Portugal, as no similar decisions have been made under other local master plans.

The Aveiro Master Plan was criticized for its weak environmental approach. The urban growth strategy for the city was devised without much attention to the fragile ecosystem. Although considered as a relevant natural area in the plan, the Ria was hardly treated as a strategic element in the integration of urban 
development and environmental sustainability [13]. In fact, apart from mandatory domestic and industrial waste treatment, no specific measures were adopted to prevent environmental impacts on the "Ria de Aveiro" by urban areas. The master plan allows high urban density levels in the vicinity of the wetland borders and includes no stricter indicators to differentiate urban development permitting in the vicinity of the "Ria de Aveiro" [13]. Given this fact, the evaluation reports could constitute an important instrument for the monitoring of urban development closer to the wetland area, specifically for the evaluation of pressures, the resulting spatial pattern of urban growth near the Ria, the environmental factors used in urban permitting and as well as necessary changes to planning performance.

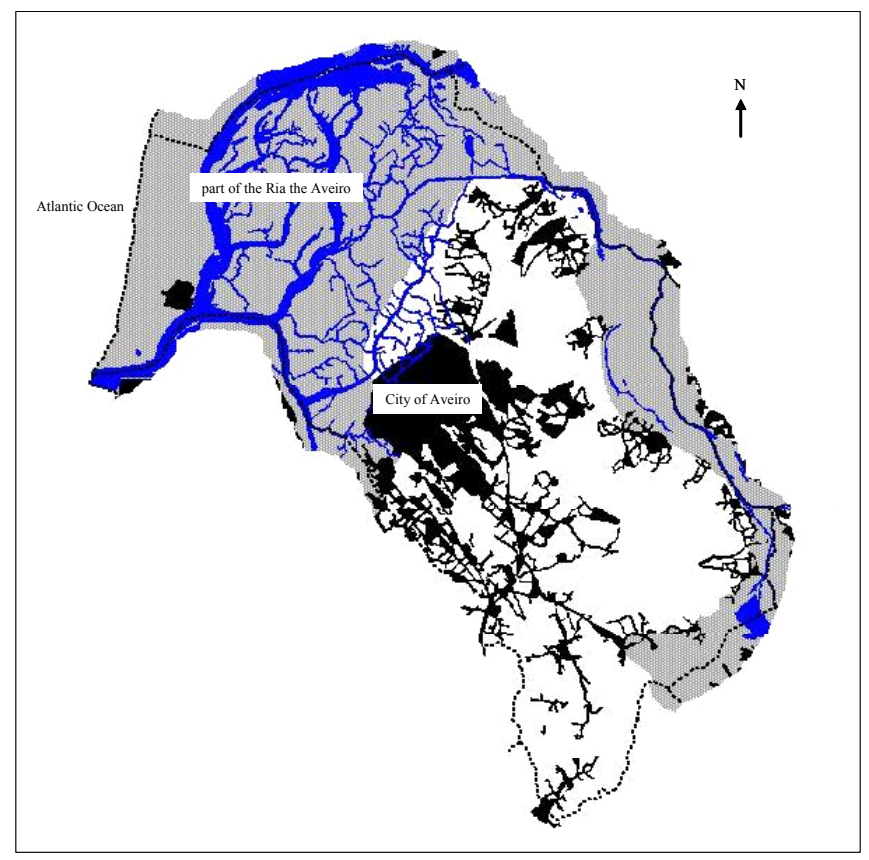

Figure 1: $\quad$ Map of the Municipality of Aveiro.

\subsection{Evaluation reports of the Aveiro Master Plan}

As a result of the decision taken by the Local Parliament, five evaluation reports on the implementation of the Local Master Plan have been prepared. They were prepared by local council technicians and submitted to the Local Parliament [14]. With some minor variations in detail, the structure and content of the first report was, in general, used in subsequent editions. Their analytical structure included objectives, assumptions, permitting, spatial analysis, evaluation and recommendations as referred in Table 1 . While the first report reveals a significant effort to critically evaluate the efficacy of the Master Plan and to 
propose recommendations, the following ones hardly do more than reiterate the main observations and give the impression of merely fulfilling bureaucratic obligations. The lack of cross analysis between the statistical data and the implementation of the plan, found in the later versions of the report, may have been influenced by the separation of the two local departments that once used to work jointly, namely the Department of Urban Management, responsible for permitting and the Department of Development and Planning, responsible for plan development.

Table 1: Main content of the evaluation reports.

\begin{tabular}{|l|l|}
\hline Objectives & $\begin{array}{l}\text { The reports focused on the need to evaluate the implementation of } \\
\text { requirements imposed by the plan and to promote a critical analysis of } \\
\text { their suitability: (i) to the requirements of current urban management, } \\
\text { (ii) to the diversity of situations faced during development control and, } \\
\text { (iii) to deal with pressures exerted on the territory. Evaluation was to } \\
\text { be carried out bearing in mind the major principles of the plan - } \\
\text { protection of quality in public spaces and in urban areas, protection of } \\
\text { urban heritage, protection of environmental and landscape quality, } \\
\text { promotion of mobility. }\end{array}$ \\
\hline Assumptions & $\begin{array}{l}\text { The reports acknowledged that the master plan had some weaknesses, } \\
\text { namely its rigidity and inadequate consideration of development trends } \\
\text { and pressures on the local territory. }\end{array}$ \\
\hline Permitting & $\begin{array}{l}\text { In the first two reports permitting analysis focused on general figures } \\
\text { for approvals of work and land parcelling projects. The simple } \\
\text { descriptive statistical analysis used failed to compare previous land use } \\
\text { figures with the new pressures exerted, or the role of local authority in } \\
\text { controlling development. In later versions, requests for declassification } \\
\text { of natural and agricultural areas were mentioned. }\end{array}$ \\
\hline $\begin{array}{l}\text { Spatial } \\
\text { analysis }\end{array}$ & $\begin{array}{l}\text { The reports included a brief description of urban development } \\
\text { pressures in the local territory, by identifying growing and dynamic } \\
\text { spots. They also included the identification of inconsistencies in the } \\
\text { delimitation of different areas, namely natural and agricultural, as well } \\
\text { as in the areas designated for tertiary activities, taking into account the } \\
\text { land-use potentials and needs. The spatial data base was very poor. }\end{array}$ \\
\hline Recommen- \\
dations
\end{tabular}


In spite of the innovative nature of the initiative, these reports dealt mainly with a statistical analysis of data related to urban land division projects and permitting. The reports analyse the figures of urban development pressures but neither compare them with past times nor analyse them in spatial terms and how they may interfere with the limits of the "Ria de Aveiro". As the soil is not an infinite or homogeneous resource, the analysis of urban permitting should be referenced to space and, time too, in order to foresee likely trends [13]. In addition, issues such as the urban density, of people or buildings, the urban and socio-economic environment, together with their implications for the various local infra-structures, were not taken into consideration. Despite their level of simplicity, the data in the reports is barely comparable which hinders any analysis of the evolution of the implementation of the Master Plan. An opportunity was lost to analyse the results of urban interventions, their spatial patterns, intensity and environmental impact.

The case study suggests the absence of a conceptual framework referred to by Hoering \& Seasons [10] during the monitoring exercise of Aveiro. It is true that an institutional requirement for monitoring has been created, (reinforced three years later by national legislation) but a clearer notion of other relevant requirements was missing. Objectives, indicators, data base, methodology and local actors' involvement were some of the weaker aspects of the process. In addition, a true notion of the reflective and humble exercise that monitoring requires was not fully incorporated in the minds of the active participants in local planning. The rational and potential of the monitoring exercise was not fully understood by those directly involved in the preparation of the reports, including local council technicians and politicians, or those responsible for the political analysis of the decision-making processes in Aveiro such as the members of the Local Parliament.

Urban monitoring and plan evaluation assume a vital relevance because the city is located next to an environmentally sensitive area. The "Ria de Aveiro" is surrounded by a set of cities which, due to the sum of their impacts may disturb the fragile ecological balance. Although a wider regional or ecosystem perspective is required, the recognition by each city of its environmental responsibility should not be neglected. This is why plan evaluation should include an analysis of the evolution of urban areas and related effects in terms of the "Ria de Aveiro". This conclusion assumed increased importance given that recent detailed urban plans and urban permitting are facilitating, if not promoting, urban density and sprawl next to the wetland and so aggravating air and noise pollution and (untreated) surface waters runoff. Plan monitoring close to sensitive areas requires, on the one hand, a clear statement of urban development objectives and environmental protection with targets and measures. On the other hand, it requires a description of the dynamics and an understanding of the motives and underlying forces of urban trends and likely environmental impacts. An argument is often made that environmental concerns should be left to mechanisms and instruments which are placed outside conventional planning process, such as the Strategic Environmental Assessment of plans. It is also common to leave monitoring of land-use and environmental related indicators to 
the Local Agendas 21 processes. Urban planning processes must eager to include sustainability issues and evaluate their development options, practices and effects. Planning processes must take into consideration, and be accountable for, the interventions on the diversity of environmental features found in the territory.

\section{Conclusions}

Increasing demand for protection of resources and greater public involvement in planning and management have contributed to the need for a better understanding of the evolution of land use and related impacts. Monitoring, allows effective land-use practices to be distinguished from less effective or harmful ones. Monitoring is necessary in order to assure the public that urban planning practices have acceptable effects on the nearby ecosystems. Frequently, statutory measures for ecosystem protection only concern the interior of natural areas and rarely propose measures for nearby sources of disruption outside their limits, such as urban areas. Moreover, urban plans often disregard these border areas, treating them as regular urban areas. This paper has focused on the relevance of urban development monitoring when a city is located in these particular circumstances. In Portugal, in 1995, the Municipality Aveiro, adopted a requirement for systematic evaluation of the implementation of its Local Master Plan. The case study revealed the lack of a conceptual framework and related components. In spite of the originality of this evaluation, the reports on the recommended evaluation processes make it clear that such evaluation processes need to be based upon clearly defined measures. Two sets of issues can be identified. One related to the planning process and plans, and the other to the monitoring process. As regards the monitoring of the planning process, the development and sustainability objectives must be clearly stated. Only then can monitoring analyse its performance. As for the monitoring process, the case study analysis revealed the need for a conceptual framework, the existence of an updated local data base and a clear statement of monitoring objectives, methodology and related indicators. The impact analysis of land-use change, urban development and environmental quality, all relevant issues in monitoring, were also issues needing more considered treatment. The relevance and potential usefulness of the monitoring exercise was not fully incorporated by either local officials. Nor was it used by the local participants, whether environmental groups, the political opposition or the public in general, to critically observe decision-making. In fact, the case study shows that plan monitoring does not depend merely on the existence of a decision to monitor but also depends upon the will and understanding of the local participants, especially those involved in the planning and decision-making processes, namely politicians, planners and technicians.

\section{References}

[1] Voogd, H., The Changing Role of Evaluation Methods in a Changing Planning Environment: Some Dutch Experiences, European Planning Studies, Vol. 5, No . 2, pp 255-265, 1997. 
[2] Bengston, D., O'Fletcher J., Nelson, K., Public policies for managing urban growth and protecting open space: policy instruments and lessons learned in the United States, Landscape and Urban Planning, 69, pp 271286, 2004.

[3] UN, Agenda 21, Report of the United Nations Conference on Environment and Development, United Nations, Rio de Janeiro, 1992.

[4] Perrings, C., Ecological Sustainability and Environmental Control, Structural Change and Economic Dynamics, 2: 275-295, 1991.

[5] Jacobs, M., The Green Economy, Environment, Sustainable Development and the Politics of the Future, Pluto Press, UK, 1991.

[6] Owens, S., "Environmental Change and Land-Use Planning", Environment and Planning A, Vol. 24, pp. 1671-1678, 1992.

[7] EEA, Europe's Environment: The Dobrís Assessment, Stanners David \& Bourdeau Philippe, Copenhagen, 1995.

[8] EEA, Towards an Urban Atlas, assessment of spatial data on 25 European cities and urban areas, Environmental Issue Report $N^{\circ} 30$, European Environmental Agency, Luxemburg, 2002.

[9] Holling, C.S., Adaptative Environmental Assessment and Management, John Wiley \& Sons, New York, 1978.

[10] Hoering, H. \& Seasons, M., Monitoring of Indicators in Local Regional Planning Practice: concepts and issues, in Planning Practice and Research, Vol. 19, N 1, pp 81-99, 2004.

[11] Sharp, E., Local State of the Environment Reporting: Lessons from experience in Britain and Canada, in Planning Practice and Research, Vol $13, \mathrm{~N}^{\circ} 1, \mathrm{pp} 81-89,1998$.

[12] Portas, N., O PDM vale a pena?, in “PDM's, PMOT's, PROT's, POOC's - Para que queremos estes planos?”, Revista Sociedade e Território, Vol. 22, pp. 31-34, 1995.

[13] Fidélis, T., Planeamento Territorial e Ambiente - o caso da Ria de Aveiro, Principia, Publicações Académicas e Científicas, Estoril, 2001.

[14] CMA, Relatórios de Execução do Regulamento do Plano Director Municipal de Aveiro, Câmara Municipal de Aveiro, Aveiro, 1997, 1999, 2000, 2001, 2002. 